\title{
The development of perception in tennis
}

\author{
Santiago Micó Salvador ${ }^{a}$, Rafael Martínez-Gallego a (1) \& José Vicente Rams ${ }^{\text {b }}$ \\ ${ }^{a}$ University of Valencia, Valencia, Spain. ${ }^{b}$ El Puig Tennis Club, Valencia, Spain.
}

\section{ABSTRACT}

This article provides coaches with a background to the concept of perception, defining it and linking it to the different components involved in certain specific motor tasks. The article then discusses theories that provide a framework to develop this aspect. Finally, it provides a practical set of specific exercises tennis players who want to improve their perceptive capacities, one of the keys to improving player performance.

\author{
Key words: perception, training, \\ tennis, exercises. \\ Received: 14 February 2020 \\ Accepted: 09 March 2020 \\ Corresponding author: Rafael \\ Martínez-Gallego, Faculty of \\ Physical Activity and Sport \\ Sciences, University of Valencia, \\ Spain. Email: \\ ramargal@hotmail.com
}

\section{INTRODUCTION}

Perception is defined as the capacity allowing the identification and acquisition of information so as to incorporate it into one's existing knowledge (Marteniuk, 1976). Perceptive processing will depend on the sensory systems (in the case of the vision, mainly the eye), on the brain, and on the conscious processing of the perceived stimuli (Palmi, 2007). Thus, the perceptive mechanism is more complex than the mere fact of receiving a stimulus (seeing, hearing, feeling...), it implies being conscious of what is being seen (perceiving).

All the actions a tennis player performs on court (motor tasks), are based on three mechanisms or phases: perception, decision, and execution (Marteniuk, 1971) (Figure 1). Therefore, depending on the difficulty of each mechanism, so will the actions tennis players perform during play be more or less complex.

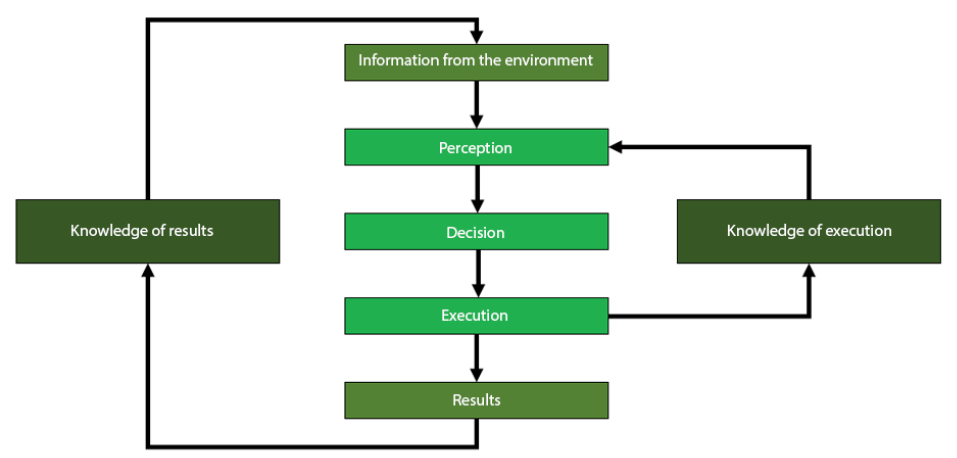

Figure 1. Mechanisms of motor tasks. Adapted from Marteniuk (1971)
Thus, perception is the first step in the process of any tennis action, and its relevance for optimum performance in the following phases of the process (decision and execution) is obvious.

Having got to this point, it is important to reflect on the time devoted to these processes during training. Even though there is no previous research on the subject, as coaches and trainers, we seem to work this process from the opposite direction, that is, devoting a great deal of time to the execution mechanism (technique) and decision mechanism (tactics), and more often than not, neglecting the perceptive mechanism, in spite of its importance.

\section{DEVELOPMENT OF THE COMPETITION}

Motor tasks may be classified according to the perceptive difficulty in self-regulation tasks, external regulation tasks and mixed regulation tasks. (Singer, 1986). Tennis could be placed among external regulation tasks, where it is necessary to continuously gather and adapt to the information received from the environment. That means to say, that because tennis is a mainly perceptive and open activity, the player cannot have a pre-set and determined specific programme of action and must constantly anticipate the ball and their opponent. Finally, the game takes place in a stable and invariable environment - the tennis court.

From a more practical view, Billing (1980) states that the perceptive difficulty of a motor skill depends on five points: 
- Number of stimuli to pay attention to: The greater the number of stimuli, the greater the difficulty.

- Number of stimuli present: The more the stimuli, the greater the difficulty.

- $\quad$ Speed/ duration of the movement: The greater the speed, the greater the difficulty.

- Size and discriminatory aspect of the stimulus (intensity): The smaller the size, the greater the difficulty.

- Time/ Extension in which the stimulus may be confusing. The shorter the time to react to a confusing stimulus, the greater the difficulty.

Applied to tennis, we have at least two stimuli: the opponent and the ball. The time and speed of the ball will greatly determine the perceptive difficulty of the game. Furthermore, the presence of the spectators or difficult weather conditions will also impact on the perceptive difficulty. In doubles, the perceptive difficulty will normally be greater due to players having to consider a greater number of stimuli, i.e. greater number of players, and on the other hand, players have less time to perceive the stimuli due to the increasing number of actions at the net.

In tennis, several studies have focused on this issue, analysing the visual and motor behaviour, visual pre-indexing, anticipation, reaction response and time, and occlusion and fixation training with players (Farrell, 1996; Crespo, 1997; Avilés et al., 2002; Del Campo et al., 2008; Del Campo et al., 2012; Del Campo et al., 2015). Williams et al. (2013) observed that training centred on perceptive skills only, as well as perceptive-executive training, improved the perceptive ability and the anticipation of beginner and intermediate players.

\section{EXERCISES PROPOSED}

The following proposed training programme is designed to improve perception, and it divides the exercises according to the variables defined by Billing (1980), classifying them into: general(G), without tennis equipment; special(E), with tennis equipment; and specific(S), taking place in game situations.

Number of stimuli to pay attention to:

\section{Exercise 1 (general)}

Cones are placed in lines (2-3 cones per row and 6+ columns) leaving a space between them. Players are asked to go over the rows (facing them or sideways, skipping, with arms forward...) whilst being directed to a particular line/column (middle, left or right), and they must say the colour of the cone in the line in order to move to the next one.
Variant: One of the cones is turned over and they should say either stay quiet or say the colour of the cone next to it, depending on the instructions.

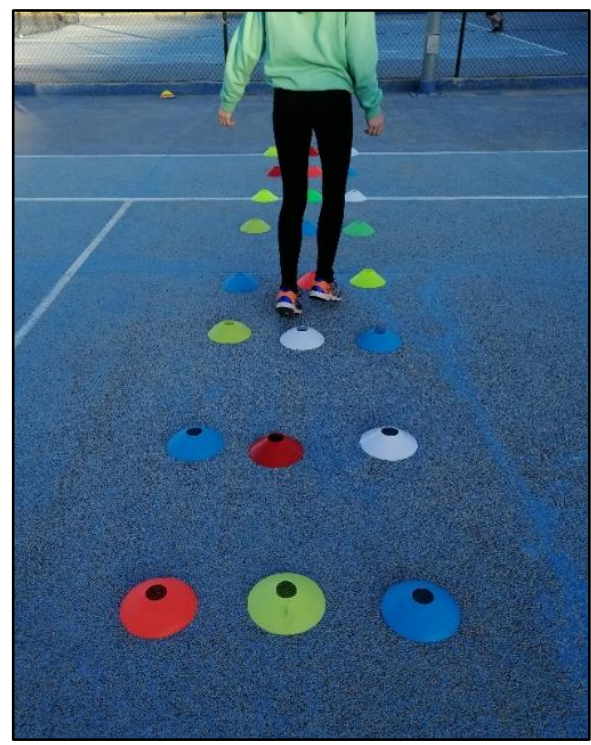

Figure 1. Exercise 1 set-up

\section{Exercise 2 (special)}

The coach throws the yellow, orange and red balls to the player at the same time, and says one or several colours. The player must catch the balls of the colours indicated (with or without a bounce).

Variant: Catch the ball of the colour indicated, without it bouncing, the other two with a bounce.

\section{Exercise 3 (specific)}

Two players rally in the centre of the court and the coach who is next to one of the players feeds balls to that player for him/her to volley back to him.

Variant: The coach feeds the balls from the other side of the court, for the player to hit back from the baseline.

\section{Number of stimuli present:}

\section{Exercise 4 (general)}

A square is formed by cones of different colours, with the player is in the centre. The coach will indicate a colour and the player must run as fast as possible to touch it.

Variant: The player will move to touch the cone while bouncing a ball. 


\section{Exercise 5 (special)}

Different types of balls will be mixed in a basket (red, orange, green, yellow). The coach feeds the balls and the player does the following progressions of exercises:

a) catch balls of a certain colour.

b) catch all the balls except those of a certain colour.

c) catch the green balls with the right hand, the red ones with the left hand.

\section{Exercise 6 (specific)}

Two players rally from the baseline while two players next to the net posts play volleys simultaneously.

Variant: Several teams of two players rally volley to volley in the doubles alleys, while the players on the baseline keep rallying.

\section{Speed/ duration of the movement}

\section{Exercise 7 (general)}

The player stands approximately $1 \mathrm{~m}$ from a wall, with a football at their feet. They must kick the ball against the wall for 30 seconds, as many times as possible.

Variant: Throwing the ball with their hands.

\section{Exercise 8 (special)}

The player, shows his back to the coach, and stands approximately $2 \mathrm{~m}$ away. The coach says turn and throws the ball at the same time, and the player will turn to catch the ball that the coach has thrown.

Variant: The coach feeds two balls with a bounce.

\section{Exercise 9 (specific)}

Players rally with a frontenis ball (much faster) or with a red ball (slower).

Variant: They rally volley to volley.

\section{Size and discriminatory aspect of the stimulus (intensity):}

\section{Exercise 10 (general)}

The word of colours are marked on the floor but the two do not correspond (e.g. the word 'red' painted in yellow) and they have to go where they are told: "X COLOUR/WORD!"
Variant: They are shown an object or shape with the colour they have to go to.

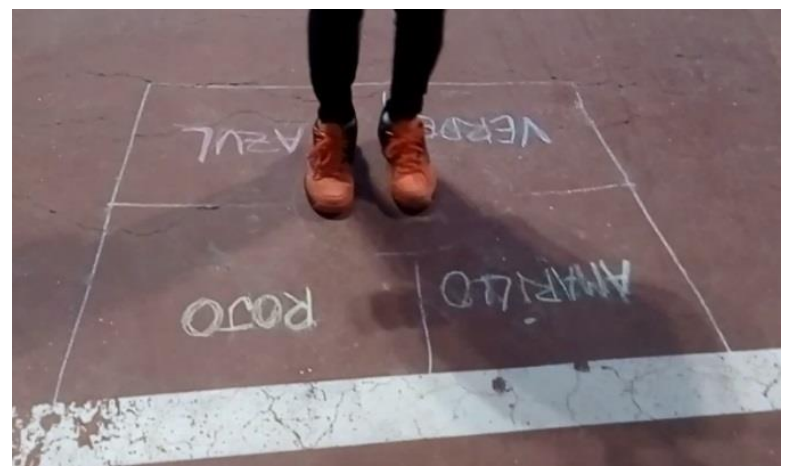

Figure 2. Exercise 10 set-up

\section{Exercise 11 (special)}

The player will have to control several balls of different sizes in different situations, e.g. a basketball with one hand, and a red ball on the racket with the other.

Variant: Vary the size/type of the balls.

\section{Exercise 12 (specific)}

Players rally with balls of different sizes, like a red ball or a squash ball.

Variant: Do the exercises with limited visibility, for example, facing the sun

\section{Time/ Extension in which the stimulus may be confusing}

\section{Exercise 13 (general)}

A "Z" ball is thrown to the player who has to catch it after its irregular bounce.

Variant: In pairs, one on each side of the net, using half of the service box, play a 7 point match. They score when the player fails to catch the ball after the first bounce, or the first bounce is outside the limited area.

\section{Exercise 14 (special)}

A player, facing a wall, will be fed balls that they will have to touch after each ball hits the wall.

Variant: Playing volleys.

Exercise 15 (specific) 
A player serves to the returner who will start with their back turned. They will turn to return at the coach's signal.

Variant: Starting with their eyes closed.

\section{CONCLUSIONS}

The development of perception plays a very important role in the acquisition and performance of any motor action, but it is especially relevant in the acquisition process of the basic motor skills. It represents the first phase of motor skill performance, and thus, it has a great influence on the decision and execution processes. Therefore, perceptive work becomes particularly relevant at early ages, playing an important role in achieving an effective long-term development of players. This article intends, on the one hand, to contextualise the importance of perception in tennis, and on the other, to provide physical trainers and coaches with some basic information that they can use as a basis to train this capacity with their players.

\section{REFERENCES}

Avilés, C., Bengugui, N., Beaudoin, E., \& Godart, F. (2002). Developing early perception and getting ready for action on the return of serve. ITF Coaching and Sport Science Review, 28(10), 6-8.

Crespo, M. (1997). What tennis research tells us about... anticipation and visual search. ITF Coaching and Sport Science Review, 12, 11-13.

Del Campo, V. L. (2008). Influencia del entrenamiento perceptivo, basado en la anticipación, sobre el comportamiento visual y la respuesta de reacción aplicado al tenis (Tesis Doctoral, Universidad de Extremadura).

Del Campo, V. L., Solana, R. S., Vaíllo, R. R., \& Hernández, F. J. M. (2012). Comportamiento visual y respuesta de reacción en tenis según el tipo y dirección del golpe. Apunts educación física y deportes, (107), 61-68, https://doi.org/10.5672/apunts.2014-0983.cat.(2012/1).107.06

Del Campo, V. L., Vaíllo, R. R., Solana, R. S., \& Hernández, F. J. M. (2015). Diferencias en el comportamiento visual y motor de tenistas en laboratorio y en pista de tenis. Revista Latinoamericana de Psicología, 47(2), 136-145, https://doi.org/10.1016/j.rlp.2015.05.003

Farrell, P. (1996). Anticipation skills and drills. ITF Coaching and Sport Science Review, 9, 13.

García-González, L., Moreno, M. P., Moreno, A., Iglesias, D., \& Del Villar, F. (2009). Estudio de la relación entre conocimiento y toma de decisiones en jugadores de tenis, y su influencia en la pericia deportiva. International Journal of Sport Sciences, 17(5), 60-75, https://doi.org/10.5232/ricyde2009.01705

Isaacs, L. \& Finch, A. (1983). Anticipatory timing of beginning and intermediate tennis player. Perceptual \& Motor Skills, 57, 451-454, https://doi.org/10.2466/pms.1983.57.2.451

Marteniuk, R. G. (1976). Information processing in motor skills. New Cork Holt, Rinehart and Winston.

Palmi, J. (2007). La percepción: enfoque funcional de la visión. Apunts.Educación Física y Deportes, 88, 81-85.

Reid, M., Quinn, A., \& Crespo, M. (2003). Fuerza y condición física para el tenis. ITF Ltd. Londres.

Williams, A. M., Ward, P., Smeeton, N. J., \& Allen, D. (2004). Developing anticipation skills in tennis using on-court instruction: Perception versus perception and action. Journal of Applied Sport Psychology, 16(4), 350-360, https://doi.org/10.1080/10413200490518002
RECOMMENDED ITF TENNIS ACADEMY CONTENT (CLICK BELOW)

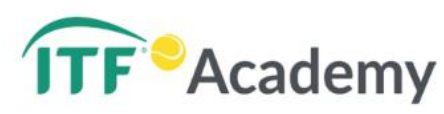

Copyright (c) 2020 Santiago Micó Salvador, Rafael Martínez-Gallego, \& José Vicente Rams

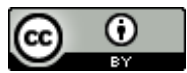

This text is under a Creative Commons BY 4.0 license

You are free to Share - copy and redistribute the material in any medium or format - and Adapt the content - remix, transform, and build upon the material for any purpose, even commercially under the following terms:

Attribution: You must give appropriate credit, provide a link to the license, and indicate if changes were made. You may do so in any reasonable manner, but not in any way that suggests the licensor endorses you or your use.

CCBY4.0license terms summary $\quad$ CCBY4.0license terms 